CLINICAL STUDY

\title{
Daily physical activity, fasting glucose, uric acid, and body mass index are independent factors associated with serum fibroblast growth factor 21 levels
}

\author{
Daniel Cuevas-Ramos ${ }^{1}$, Paloma Almeda-Valdes ${ }^{1}$, Francisco J Gómez-Pérez ${ }^{1}$, Clara Elena Meza-Arana ${ }^{2}$, \\ Ivette Cruz-Bautista $^{1}$, Olimpia Arellano-Campos ${ }^{1}$, Mariana Navarrete-López ${ }^{1}$ and Carlos A Aguilar-Salinas ${ }^{1}$ \\ Departments of ${ }^{1}$ Endocrinology and Metabolism and ${ }^{2}$ Internal Medicine, Instituto Nacional de Ciencias Médicas y Nutrición 'Salvador Zubiran', \\ Vasco de Quiroga 15, Seccion XVI, Tlalpan, 14000 Mexico DF, Mexico
}

(Correspondence should be addressed to C A Aguilar-Salinas; Email: caguilarsalinas@yahoo.com)

\begin{abstract}
Objective: Fibroblast growth factor 21 (FGF21) levels have been linked with beneficial effects on glucose and lipid metabolism in animals. It is elevated in humans with the metabolic syndrome. This study investigates independent factors associated with serum FGF21 levels.

Design: Cross-sectional study done in healthy blue-collar workers.

Methods: A medical history was taken, and FGF21 (measured using an ELISA commercial kit), glucose, uric acid, plasma lipids, total/high-molecular weight (HMW) adiponectin, and retinal-binding protein 4 (RBP4) were measured in 210 individuals with $(n=81)$ and without $(n=129)$ metabolic syndrome. Results: The median of serum FGF21 levels were higher in subjects with metabolic syndrome ( 339.5 vs $276.4 \mathrm{ng} / \mathrm{l}, P=0.01)$. Serum FGF21 levels correlated positively with body mass index (BMI; $r=0.23$, $P=0.001)$ and age $(r=0.17, P=0.01)$. After adjusting for age and BMI, a significant positive correlation persisted for fasting glucose, uric acid, and physical activity in both males $(r=0.21$, $r=0.11$, and $r=0.19$, all $P<0.05)$ and females $(r=0.20, r=0.19$, and $r=0.14$, all $P<0.05)$. In addition, FGF21 also correlates negatively with RBP4 $(r=-0.27, P=0.02)$, total $(r=-0.26$, $P=0.03)$, and HMW adiponectin $(r=-0.30, P=0.01)$ in women. A multiple linear regression model analysis identified that BMI (standardized $\beta(\mathrm{SB})=0.247 ; P=0.008)$, glucose $(\mathrm{SB}=0.226 ; P=0.003)$, uric acid $(\mathrm{SB}=0.191 ; P=0.04)$, and physical activity $(\mathrm{SB}=0.223 ; P=0.004)$ are independent factors influencing serum FGF21 levels $\left(F=10.05, r^{2}=0.19, P<0.001\right)$. In addition, fasting hyperglycemia $\geq 100 \mathrm{mg} / \mathrm{dl}$, excess body weight with $\mathrm{BMI} \geq 25 \mathrm{~kg} / \mathrm{m}^{2}$, and uric acid $\geq 5.5 \mathrm{mg} / \mathrm{dl}$ predicted higher serum FGF21 levels.

Conclusion: Serum FGF21 levels are influenced by BMI, fasting glycemia, uric acid, and physical activity.
\end{abstract}

European Journal of Endocrinology 163 469-477

\section{Introduction}

Fibroblast growth factor 21 (FGF21), a member of the FGF family, has recently emerged as a novel regulator of metabolism (1). FGF21 is mainly produced by the liver (2), and functions as a potent activator of glucose uptake in adipocytes (1). FGF21 causes paracrine effects, such as induction of hepatic ketogenesis, and endocrine actions, such as the promotion of lipolysis in white adipose tissue $(3,4)$, although this last effect is controversial (5). Moreover, when FGF21 is over expressed in transgenic mice, it protects animals from diet-induced obesity, and its administration in diabetic rodents (1) and monkeys (6) lowers blood glucose and triglyceride levels. FGF21 has been shown to produce a significant increment in total adiponectin and a reduction in leptin levels as well (6).
The expression and release of FGF21 from liver are regulated by the peroxisome proliferator-activated receptor- $\alpha$ (PPAR- $\alpha$ or PPARA as listed in the HUGO Database) in liver $(3,4)$. Accordingly, free fatty acids appear to be major regulators of FGF21 expression, acting via PPAR- $\alpha$-dependent activation of the FGF21 gene (7). This effect of fatty acids may explain the induction of FGF21 after fasting, and the paradoxically high levels of FGF21 reported recently in patients with type 2 diabetes and obesity $(8,9)$. However, other clinical studies in humans have shown inconsistent results. Positive correlations between FGF21 levels and some obesity traits such as body mass index (BMI), waist circumference, waist-to-hip ratio, and fat percentage have been reported $(9,10)$. On the other hand, similar correlations were not found in patients with a recently diagnosed type 2 diabetes mellitus (11). While some 
studies suggest a role for FGF21 in insulin sensitivity $(1,5)$, other studies using more reliable methodology (i.e. hyperglycemic clamp) do not confirm this association (10). Although current data support the role of FGF21 as a metabolic regulator of glucose uptake (1), adiposity, and lipid metabolism $(3,4)$, more investigation is needed to clarify the action, regulation, and clinical relevance of FGF21. The relationships between FGF21 and physical activity, serum adipokines (such as retinalbinding protein 4 (RBP4) and high-molecular weight (HMW) adiponectin) and other traits of the metabolic syndrome besides glycemia and lipid parameters have not been investigated in humans. An increased serum RBP4 concentration has been reported in subjects with the metabolic syndrome (12). However, not all studies are concordant, and some did not observe a relationship between RBP4 and insulin resistance (13). Adiponectin modulates a number of metabolic processes, including glucose regulation and fatty acid catabolism (14). Adiponectin self-associates into larger structures, and studies on multimer formation in human blood have demonstrated that HMW adiponectin is the active form of the protein (15). The levels of both total and HMW adiponectin are lower when metabolic syndrome is present and usually higher in women than in men (16).

This study is aimed to investigate independent factors associated with serum FGF21 levels and the possible association of FGF21 with other parameters of insulin resistance, physical activity, and adiposity.

\section{Materials and methods}

\section{Study subjects}

A total of 210 Mexican Mestizos were recruited for this study. The population consisted of medium-income healthy workers without a personal history of metabolic abnormalities. Evaluations were scheduled in advance. The individuals were studied at their place of work in a properly conditioned area. We included all individuals who agreed to be evaluated, of both genders, between 18 and 65 years of age. We excluded subjects with current treatment for diabetes, dyslipidemia, hypertension, thyroid diseases, or obesity in order to eliminate the possible effect of medications on clinical and biochemical parameters. In addition, we also excluded subjects with other chronic disease (such as HIV infection or viral hepatitis, lupus or rheumatoid arthritis, seizures, major depression with treatment, hospitalization in last 6 months, active cancer or under treatment, and pregnant women). Individuals with severe hypertriglyceridemia and a lipemic serum were also excluded since it could interfere with biochemical results.

The metabolic syndrome was defined according to the US 2004 National Cholesterol Education Program (NCEP) Adult Treatment Panel III guidelines (17) and modified as recommended in the latest American Heart Association/National Heart, Lung, and Blood Institute
Scientific Statement for fasting glucose (18). The metabolic syndrome was defined as the presence of three or more of the following risk factors: i) central obesity (waist circumference $\geq 88 \mathrm{~cm}$ in women and $\geq 102 \mathrm{~cm}$ in men); ii) hypertriglyceridemia (fasting triglycerides $\geq 150 \mathrm{mg} / \mathrm{dl}(\geq 1.69 \mathrm{mmol} / \mathrm{l})$; iii) low high-density lipoprotein (HDL) cholesterol $<50 \mathrm{mg} / \mathrm{dl}(<1.29 \mathrm{mmol} / \mathrm{l})$ in women and $<40 \mathrm{mg} / \mathrm{dl}$ (1.04 mmol/l) in men); iv) hyperglycemia (fasting glucose $\geq 100 \mathrm{mg} / \mathrm{dl}$ ( $\geq 5.6 \mathrm{mmol} / \mathrm{l})$; and $\mathrm{v}$ ) hypertension (sitting blood pressure of 130/85 mmHg or more, taken as a mean of two readings obtained after a resting for at least $10 \mathrm{~min}$ ). The human research ethics committee of our institution approved the study. All procedures were done in accordance with the Declaration of Helsinki. Informed consent was obtained from all subjects.

\section{Biochemical and anthropometric measurements}

The Endocrinology and Metabolism Department of the Instituto Nacional de Ciencias Médicas y Nutrición Salvador Zubirán (INCMNSZ) performed all biochemical laboratory measurements using standardized procedures. The measurements were performed with commercially available standardized methods. This laboratory is certified for standardization of the tests by the External Comparative Evaluation of Laboratories Program of the College of American Pathologists. Glucose, total cholesterol, HDL cholesterol, triglycerides, and uric acid were measured using the Synchron CX analyzer (Beckman Systems, Fullerton, CA, USA). The coefficients of variation for cholesterol and HDL cholesterol were 3.3 and $2.5 \%$ respectively. Low-density lipoprotein cholesterol concentration was estimated by the Friedewald formula. Plasma insulin concentrations were estimated using a RIA method (MEIA, Abbott Laboratories). High-sensitivity C-reactive protein (CRP) was measured in plasma in duplicate using a particleenhanced immunoturbidimetric assay (Roche Diagnostics). A human FGF21 ELISA kit was used (BioVendor Laboratory Medicine, Modrice, Czech Republic) that do not showed cross-reactivity with other members of the human FGF family, basic FGF and adipokines such as adiponectin, leptin, and RBP4. For the measurement of FGF21, serum samples were diluted 1:3 before the assay, and then $100 \mu$ liluted sera, calibrators, and quality controls were added to 96-well microtiter plates coated with an affinity-purified polyclonal anti-human FGF21 antibody. The intra- and inter-assay variations were 5.1 and $6.6 \%$ respectively. Serum total and HMW adiponectin (Millipore, Billarica, MA, USA), leptin (Millipore), and RBP4 (AdipoGen, Inc., Incheon, Korea) were determined by a sandwich ELISA kit respectively. Insulin resistance was estimated using homeostasis model assessment index-insulin resistance (HOMA-IR) (19). Anthropometric measurements were done after participants removed their shoes and upper garments. 
Body weight and fat was quantified with the UM-026 Tanita Body Composition Analyzer (Tanita, Tokyo, Japan). All subjects were instructed to stand in the center of the scale during weight assessment. Height was obtained using the floor scale's stadiometer. Height was measured to the nearest $0.5 \mathrm{~cm}$. BMI was calculated as weight $(\mathrm{kg})$ divided by height $\left(\mathrm{m}^{2}\right)$. Abdominal circumference was measured to the nearest $0.1 \mathrm{~cm}$ at the level of the greatest frontal extension of the abdomen between the bottom of the rib cage and the top of the iliac crest. All subjects underwent physical examinations and routine biochemical analyses after overnight fasting between 8 and $12 \mathrm{~h}$.

\section{Physical activity}

Subjects were instructed to answer a physical activity questionnaire developed by Tremblay and colleagues at Laval University (Canada). This questionnaire had been validated previously in a Mexican population (20). The questionnaire quantifies the physical activity level (kcal/day or in $\mathrm{kJ}$ if $\mathrm{kcal}$ is multiplied by 4.1855) throughout a 24-h period. Every subject answered three questionnaires distributed over two labor days and one day of the weekend. The individual chose from 1 (lowest) to 9 (highest) depending on the intensity of physical activity done in periods of $15 \mathrm{~min}$, and wrote down the information in a specified table. Each number is multiplied by a constant that represents the calculated energetic expenditure in those $15 \mathrm{~min}$. These results were added together, and the $\mathrm{kcal} /$ day estimate was obtained. The questionnaire has a sensitivity to detect changes of $4.7 \mathrm{kcal} / \mathrm{kg}$ per day $(20 \mathrm{~kJ} / \mathrm{kg}$ per day). The intra-individual reproducibility $(r=0.88, P<0.001)$ and interclass correlation coefficient $(0.86 ; P<0.001)$ were higher when these were compared with similar instruments $(21,22)$. Physical activity was measured in $167(79.5 \%)$ of the 210 patients.

\section{Statistical analysis}

Normally distributed data, determined using Kolmogorov-Smirnov test, were expressed as means and s.D. ( \pm s.D.), whereas variables with a skewed distribution were reported as median (interquartile range) and

Table 1 Clinical and biochemical characteristics of the study sample stratified by the presence of the metabolic syndrome $(n=210)$. Data are expressed as mean \pm s.D. or as median (interquartile range).

\begin{tabular}{|c|c|c|c|}
\hline Variable & Controls $(n=129)$ & Metabolic syndrome $(n=81)$ & $P$ value \\
\hline Age (years) & $36.2 \pm 10.3$ & $41.5 \pm 9.1$ & 0.001 \\
\hline $\operatorname{Sex}(M / F)$ & $44 / 85$ & $37 / 44$ & 0.116 \\
\hline $\mathrm{BMI}\left(\mathrm{kg} / \mathrm{m}^{2}\right)$ & $22.8 \pm 1.8$ & $29.0 \pm 3.8$ & $<0.001$ \\
\hline Serum FGF21 ${ }^{\mathrm{a}}(\mathrm{ng} / \mathrm{l})$ & $276.4(169.0-404.4)$ & $339.5(248.0-492.7)$ & 0.01 \\
\hline \multirow[t]{2}{*}{ Serum RBP4 ${ }^{\mathrm{a}}(\mathrm{ng} / \mathrm{ml})$} & M: $70.7(50.1-83.5)$ & M: $53.3(31.9-74.0)$ & 0.04 \\
\hline & $F: 47.8(33.4-70.4)$ & $F: 46.1(38.5-67.3)$ & 0.77 \\
\hline \multirow[t]{2}{*}{ Serum adiponectin ${ }^{\mathrm{a}}(\mathrm{ng} / \mathrm{ml})$} & M: $7.8(5.8-10.2)$ & $\mathrm{M}: 6.8(5.4-8.4)$ & 0.02 \\
\hline & $\mathrm{F}: 11.0(8.4-13.0)$ & $\mathrm{F}: 9.3(7.0-12.3)$ & 0.12 \\
\hline \multirow{2}{*}{ Serum HMWA ${ }^{a}(\mathrm{ng} / \mathrm{ml})$} & $\mathrm{M}: 3.5(2.0-4.9)$ & $M: 3.5(2.2-5.1)$ & 0.76 \\
\hline & $F: 5.8(4.5-9.1)$ & $F: 5.4(3.7-8.1)$ & 0.08 \\
\hline \multirow[t]{2}{*}{ Leptin $^{\mathrm{a}}(\mathrm{ng} / \mathrm{ml})$} & M: $8.4(6.9-10.0)$ & M: $12.7(7.2-21.0)$ & 0.01 \\
\hline & F: $20.7(16.9-32.4)$ & $F: 25.7(16.6-35.6)$ & 0.18 \\
\hline Serum hsCRPa (mg/l) & $1.1(0.6-2.0)$ & $2.2(1.4-4.7)$ & $<0.001$ \\
\hline \multirow[t]{2}{*}{ Waist circumference $(\mathrm{cm})$} & M: $89.7 \pm 4.7$ & M: $97.7 \pm 9.0$ & $<0.001$ \\
\hline & $F: 79.8 \pm 5.9$ & $F: 93.6 \pm 9.7$ & $<0.001$ \\
\hline \multirow{2}{*}{ Waist-to-hip ratio } & M: $0.90 \pm 0.03$ & M: $0.93 \pm 0.04$ & 0.01 \\
\hline & $F: 0.83 \pm 0.1$ & $F: 0.86 \pm 0.05$ & 0.13 \\
\hline \multirow[t]{2}{*}{ Fat percentage $(\%)^{\mathrm{b}}$} & $M: 21.5 \pm 2.7$ & $M: 29.8 \pm 5.4$ & $<0.001$ \\
\hline & $F: 27.5 \pm 4.3$ & $F: 37.5 \pm 6.1$ & $<0.001$ \\
\hline Systolic blood pressure (mmHg) & $103.6 \pm 12.4$ & $111.5 \pm 14.5$ & 0.001 \\
\hline Diastolic blood pressure (mmHg) & $69.47 \pm 9.9$ & $74.9 \pm 11.2$ & 0.002 \\
\hline Cholesterol (mg/dl) & $202.0 \pm 40.2$ & $209.0 \pm 41.8$ & 0.29 \\
\hline Triglycerides $^{\mathrm{a}}(\mathrm{mg} / \mathrm{dl})$ & $113.0(92-148.0)$ & $161(116-247)$ & $<0.001$ \\
\hline LDL cholesterol $(\mathrm{mg} / \mathrm{dl})$ & $122.8 \pm 32.3$ & $130.8 \pm 30.6$ & 0.13 \\
\hline \multirow[t]{2}{*}{ HDL cholesterol (mg/dl) } & $M: 43 \pm 5.8$ & $M: 37.9 \pm 9.2$ & 0.009 \\
\hline & $F: 53.5 \pm 12.7$ & $F: 45.0 \pm 10.5$ & $<0.001$ \\
\hline Fasting insulin ${ }^{a}$ (mIU/l) & $6.5(4.5-7.8)$ & $10.8(8.0-15.5)$ & $<0.001$ \\
\hline HOMA-IR ${ }^{a}$ & $1.26(0.91-1.6)$ & $2.3(1.7-3.5)$ & $<0.001$ \\
\hline Fasting glucose (mg/dl) & $84.6 \pm 8.2$ & $89.0 \pm 9.4$ & 0.003 \\
\hline Physical activity (kcal/kg per day) & $55.2(47.7-69.6)$ & $50.9(46.8-55.7)$ & $<0.01$ \\
\hline Physical activity (kcal/day) & $2894.5(2349-3378)$ & $3905.2(3312.8-4502)$ & $<0.001$ \\
\hline \multirow[t]{2}{*}{ Uric acid (mg/dl) } & M: $6.2 \pm 1.3$ & $\mathrm{M}: 6.6 \pm 1.19$ & 0.22 \\
\hline & $F: 4.6 \pm 0.93$ & $F: 5.1 \pm 0.90$ & 0.001 \\
\hline Creatinine (mg/dl) & $0.89 \pm 0.15$ & $0.90 \pm 0.15$ & 0.85 \\
\hline
\end{tabular}

HMWA, high-molecular weight adiponectin; RBP4, retinal-binding protein 4; hsCRP, high-sensitivity C-reactive protein; M, male; F, female.

aLog-transformed before analysis.

b Included 160 subjects with available data (63 men and 97 women). 
log-transformed to approximate normality before analysis. The $\chi^{2}$, Student unpaired $t$-test, or MannWhitney $U$ test was used as appropriate for comparison between the two groups. Homogeneity of variance was evaluated with Levene's test. Correlation coefficients between FGF21 and metabolic features were evaluated in all participants, and were calculated using Spearman's, Pearson's $r$ tests or using partial correlation analysis when adjusted for age and BMI. One-way ANOVA was used for comparison between serum levels of FGF21 and number of components of metabolic syndrome and physical activity level. Serum FGF21 levels were adjusted for age, BMI, and physical activity. Stepwise linear regression model was used to examine the impact of variables in serum FGF21 level. Homogeneity and linearity were confirmed through the pattern of studentized residuals plotted against adjusted predicted values. No correlation was seen between them $(r=-0.062, P=0.42)$. The variables selected to enter into regression analyses were those that correlated significantly with serum FGF21 (Table 2). The mean of uric acid values in both groups was used as cutoff $(5.5 \mathrm{mg} / \mathrm{dl})$. All reported $P$ values are based on two-sided tests considering $\leq 0.05$ as significant. All analyses were performed with SPSS 15.0 (Chicago, IL, USA).

\section{Results}

The characteristics of the study population are shown in Table 1 . The metabolic syndrome group included 81 individuals (44 females and 37 males) with a mean age of $41.5 \pm 9.1$ years and BMI of $29.0 \pm 3.8 \mathrm{~kg} / \mathrm{m}^{2}$. The control group included 129 individuals (85 females and 44 males) with a mean age of $36.2 \pm 10.3$ years and BMI of $22.8 \pm 1.8 \mathrm{~kg} / \mathrm{m}^{2}$. Serum FGF21 levels ranged from 47 to $1839 \mathrm{ng} / \mathrm{l}$. Serum FGF21 levels were significantly higher $(P=0.01)$ in subjects with the metabolic syndrome (339.5 ng/l (248.0-492.7)) in comparison with patients without it $(276.4 \mathrm{ng} / \mathrm{l}$ (169.0-404.4)). There was no sex difference in serum FGF21 levels. In the whole population, serum FGF21 levels had significant positive association with age $(r=0.17, P=0.01)$, glucose $(r=0.29, P<0.001)$, BMI $(r=0.23, P=0.001)$, fat percentage $(r=0.19$, $P=0.01)$, insulin $(r=0.13, P=0.05)$, HOMA-IR $(r=0.16, P=0.01)$, triglycerides $(r=0.15, P=0.02)$, HDL cholesterol $(r=-0.15, P=0.02)$, systolic blood pressure $(r=0.19, P=0.006)$, uric acid $(r=0.17$, $P=0.008$ ), and physical activity (expressed as kcal/day, $r=0.29, P=0.04)$. No association was identified between FGF21 and high-sensitivity CRP (hsCRP). After adjusting for age and BMI, a significant positive correlation persisted only for fasting glucose, uric acid, and physical activity (Fig. 1). This was true also in males or females (Table 2). The association between FGF21 and glucose was stronger in the subgroup of patients with metabolic syndrome $(n=81, r=0.30, P=0.006)$.
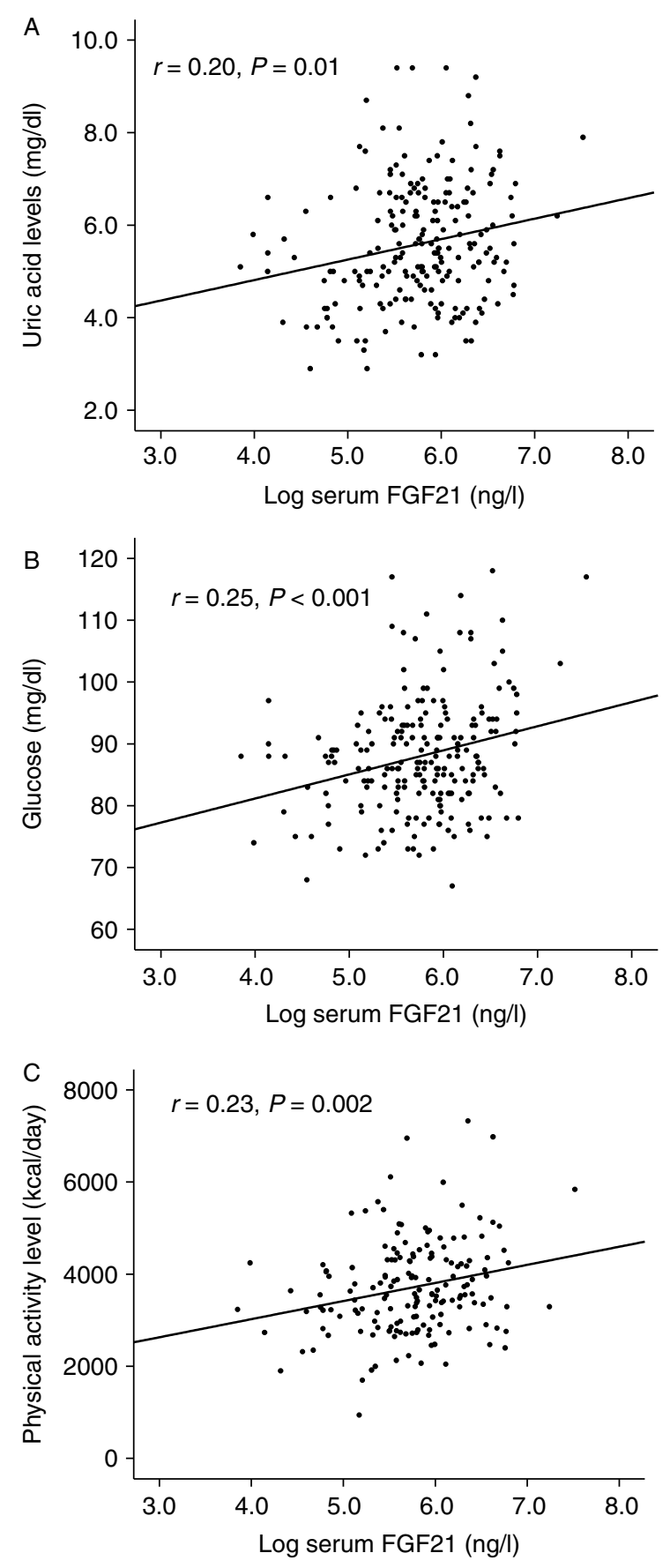

Figure 1 Correlation (adjusted for age and $\mathrm{BMI}$ ) of the log serum levels of FGF21 with uric acid (A), glucose (B), and physical activity (C) in 210 Mexican subjects.

\section{Physical activity, glucose, uric acid, and BMI influence serum FGF21 levels}

Stepwise linear regression model identified that BMI, glucose, uric acid, and physical activity (kcal/day) were independent factors associated with serum FGF21 levels $\left(F=10.05 ; \quad r^{2}=0.199, \quad P<0.001 ;\right.$ Table 3$)$. 
Table 2 Correlations of serum fibroblast growth factor 21 (FGF21) levels with cardiometabolic risk factors in all sample studied ( $n=210)$.

\begin{tabular}{|c|c|c|c|c|c|c|}
\hline & \multicolumn{2}{|c|}{ Serum FGF21 ${ }^{a}$} & \multicolumn{2}{|c|}{$\begin{array}{l}\text { Serum FGF21 } \\
\text { (age-adjusted) }\end{array}$} & \multicolumn{2}{|c|}{$\begin{array}{c}\text { Serum FGF21 } \\
\text { (age- and BMI-adjusted) }\end{array}$} \\
\hline & $r$ & $P$ & $r$ & $P$ & $r$ & $P$ \\
\hline \multicolumn{7}{|l|}{ Age } \\
\hline Males & 0.26 & 0.02 & - & - & - & - \\
\hline Females & 0.18 & 0.03 & & & & \\
\hline \multicolumn{7}{|l|}{ BMI } \\
\hline Males & 0.20 & 0.04 & 0.29 & 0.02 & - & - \\
\hline Females & 0.28 & 0.001 & 0.31 & 0.003 & & \\
\hline \multicolumn{7}{|c|}{ Waist circumference } \\
\hline Males & 0.16 & 0.15 & 0.22 & 0.09 & -0.08 & 0.52 \\
\hline Females & 0.28 & 0.001 & 0.34 & 0.001 & 0.15 & 0.15 \\
\hline \multicolumn{7}{|c|}{ Waist-to-hip ratio } \\
\hline Males & 0.03 & 0.75 & -0.11 & 0.53 & -0.10 & 0.58 \\
\hline Females & 0.15 & 0.07 & 0.14 & 0.23 & -0.11 & 0.35 \\
\hline \multicolumn{7}{|c|}{ Fat percentage } \\
\hline Males & 0.35 & 0.005 & 0.32 & 0.01 & 0.14 & 0.29 \\
\hline Females & 0.24 & 0.01 & 0.23 & 0.03 & 0.00 & 0.94 \\
\hline \multicolumn{7}{|c|}{ Fasting glucose } \\
\hline Males & 0.32 & 0.004 & 0.48 & 0.04 & 0.21 & 0.02 \\
\hline Females & 0.20 & 0.018 & 0.34 & 0.008 & 0.20 & 0.009 \\
\hline \multicolumn{7}{|c|}{ Fasting insulin ${ }^{a}$} \\
\hline Males & 0.07 & 0.52 & 0.09 & 0.46 & -0.07 & 0.57 \\
\hline Females & 0.15 & 0.07 & 0.14 & 0.17 & -0.01 & 0.91 \\
\hline \multicolumn{7}{|l|}{ HOMA-IR } \\
\hline Males & 0.11 & 0.29 & -0.14 & 0.43 & -0.13 & 0.47 \\
\hline Females & 0.17 & 0.04 & 0.003 & 0.97 & -0.11 & 0.35 \\
\hline \multicolumn{7}{|c|}{ Triglycerides $^{\mathrm{a}}$} \\
\hline Males & 0.07 & 0.48 & -0.01 & 0.93 & 0.00 & 0.99 \\
\hline Females & 0.17 & 0.04 & 0.02 & 0.86 & -0.02 & 0.82 \\
\hline \multicolumn{7}{|c|}{ HDL cholesterol } \\
\hline Males & -0.13 & 0.22 & -0.05 & 0.69 & 0.04 & 0.71 \\
\hline \multicolumn{6}{|l|}{ hsCRPa } & 0.29 \\
\hline $\begin{array}{l}\text { hsCRPa }^{a} \\
\text { Males }\end{array}$ & -0.05 & 0.76 & -0.11 & 0.53 & -0.95 & 0.61 \\
\hline Females & -0.05 & 0.65 & -0.04 & 0.72 & -0.14 & 0.23 \\
\hline \multicolumn{7}{|c|}{ Total adiponectin ${ }^{\mathrm{a}}$} \\
\hline Males & 0.16 & 0.13 & 0.04 & 0.76 & 0.08 & 0.59 \\
\hline Females & -0.12 & 0.04 & -0.26 & 0.02 & -0.26 & 0.03 \\
\hline \multicolumn{7}{|c|}{ HMW adiponectin ${ }^{a}$} \\
\hline Males & 0.08 & 0.48 & 0.00 & 0.96 & 0.03 & 0.84 \\
\hline Females & -0.15 & 0.03 & -0.32 & 0.006 & -0.30 & 0.01 \\
\hline \multicolumn{7}{|l|}{ RBP4 $^{\mathrm{a}}$} \\
\hline Males & 0.04 & 0.77 & -0.03 & 0.81 & 0.09 & 0.52 \\
\hline Females & -0.24 & 0.03 & -0.29 & 0.01 & -0.27 & 0.02 \\
\hline \multicolumn{7}{|l|}{ Leptin $^{\mathrm{a}}$} \\
\hline Males & 0.02 & 0.84 & 0.01 & 0.92 & -0.23 & 0.08 \\
\hline \multirow{2}{*}{\multicolumn{7}{|c|}{ Uric acid }} \\
\hline & & & & & & \\
\hline Males & 0.31 & 0.02 & 0.44 & 0.04 & 0.11 & 0.03 \\
\hline Females & 0.23 & 0.007 & 0.27 & 0.01 & 0.19 & 0.03 \\
\hline \multicolumn{7}{|c|}{ Physical activity (kcal/day) } \\
\hline Males & 0.21 & 0.03 & 0.22 & 0.03 & 0.19 & 0.01 \\
\hline Females & 0.23 & 0.01 & 0.22 & 0.04 & 0.14 & 0.009 \\
\hline
\end{tabular}

BMI, body mass index; HDL, high-density lipoprotein; hsCRP, high-sensitivity C-reactive protein; HMW, high molecular weight; RBP4, retinal-binding protein 4. a Log-transformed before analysis.

There was a progressive increment in serum FGF21 levels (adjusted for age and BMI) with increasing intensity of physical activity $(F=4.8, \quad P=0.009$; Fig. 2). We also examined the combined effects of BMI, glucose, and uric acid on serum FGF21 levels according to the level of physical activity.
As summarized in Table 4, fasting hyperglycemia $\geq 100 \mathrm{mg} / \mathrm{dl}$, excess body weight with BMI $\geq 25 \mathrm{~kg} / \mathrm{m}^{2}$, and uric acid $\geq 5.5 \mathrm{mg} / \mathrm{dl}$ predicted higher serum FGF21 levels in comparison with subjects without these abnormalities. Moreover, a further increment in serum FGF21 levels was observed when 
Table 3 Multiple stepwise regression analysis of variables independently associated with serum fibroblast growth factor 21 (FGF21) levels.

\begin{tabular}{lccc}
\hline $\begin{array}{l}\text { Independent } \\
\text { variables }\end{array}$ & Standardized $\boldsymbol{\beta}$ & $\boldsymbol{t}$ & $\boldsymbol{P}$ value \\
\hline BMI & 0.247 & 2.696 & 0.008 \\
Glucose & 0.226 & 2.971 & 0.003 \\
Uric acid & 0.191 & 2.180 & 0.04 \\
Physical activity & 0.223 & 2.943 & 0.004 \\
\hline
\end{tabular}

The analysis also included age, waist circumference, fat percentage, insulin, leptin, RBP4, and adiponectin, which were all excluded in the final model. Physical activity expressed as kcal/day. Parameters of the model: $F=10.05$; $r^{2}=0.199, P<0.001$.

the clinical or biochemical abnormality coexisted with higher intensity of daily physical activity.

We confirmed a dose-effect relationship between serum FGF21 levels (adjusted for age, BMI, and physical activity) and the number of the metabolic syndrome traits (Fig. 2). The association remained significant even after adjusting for individual components of the syndrome, except for waist circumference (Supplementary Tables 1 and 2, see section on supplementary data given at the end of this article).

\section{Serum FGF21 levels and adipocytokines}

In the whole population, no significant correlation was identified between FGF21 and leptin, RBP4, HMW, and total adiponectin. However, after adjusting for age, gender, and BMI, a significant association was identified for RBP4 $(r=-0.35, P=0.02)$, total $(r=-0.23$, $P=0.01)$, and HMW adiponectin $(r=-0.34$, $P=0.03)$. After gender stratification, the association between FGF2 1 and RBP4 $(r=-0.27, P=0.02)$, total $(r=-0.26, P=0.03)$, and HMW $(r=-0.30, P=0.01)$ adiponectin persisted only in women (Table 2). In addition, FGF21 correlated more significantly with RBP4 $(r=-0.48, \quad P=0.003)$, total $(r=-0.39$, $P=0.01)$, and HMW adiponectin $(r=-0.49$,
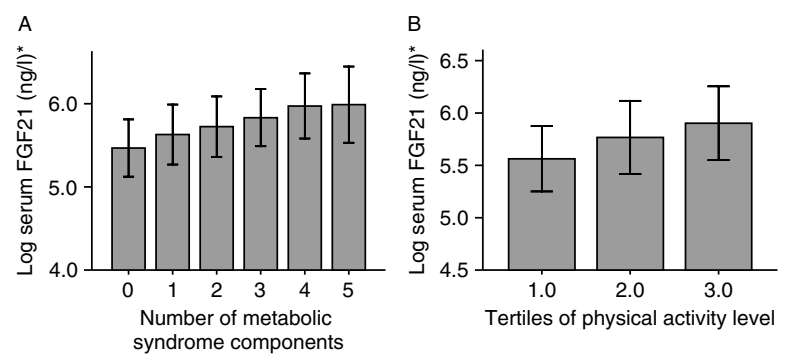

Figure 2 Log serum FGF21 levels according to the number of metabolic syndrome components (*adjusted for age, BMI, and physical activity) and tertiles of physical activity (kcal/day) level ( ${ }^{*}$ adjusted for age and BMI). Data are shown as means \pm S.D. Results of one-way ANOVA for metabolic syndrome: $F=16.5$, $P<0.001$; for physical activity level: $F=4.8, P=0.009$.
$P=0.002)$ in the subgroup of women with central obesity $(n=106)$. The association between FGF 21 and these adipokines was not identified in men $(r=0.09$, $r=0.08$, and $r=0.03$ respectively, all $P>0.05$ ).

\section{Discussion}

FGF21 is a recently identified player in carbohydrate and lipid metabolism $(2,10,11)$. Its physiological relevance in humans is still under study. Here, we report an independent association between serum FGF21 levels and fasting plasma glucose, BMI, uric acid, and physical activity. Additionally, in women, we found that as FGF21 increased, levels of RBP4, total and HMW adiponectin decreased.

In animal models, Fgf 21 mRNA concentrations are significantly induced by fasting and in the presence of increased concentrations of free fatty acids. This process appears to be mediated through the activation of the PPAR- $\alpha(10,11,23)$. FGF21 in turn has diverse effects including the stimulation of gluconeogenesis (but not glycogenolysis), fatty acid oxidation, lipolysis, and ketogenesis (24); inhibition of lipogenesis (25); the induction of a hibernation-like state of torpor (11); and blunting of the GH-signaling pathway (26). FGF21 also increases glucose utilization (through the AKT pathway) in fat and muscle (27). In summary, the secretion of this hormone improves the utilization of energy substrates (fatty acids, ketones, and glucose), and interferes with energy consuming processes (i.e. lipogenesis and growth). For example, Badman et al. (10) have reported a deficient long-term adaptation to ketosis in FGF21-deficient mice. A similar physiological process may occur in humans, since FGF21 concentrations are increased after a prolonged fast (28).

In line with previous reports, our results confirm that FGF21 concentrations are increased in the metabolic syndrome $(6,7)$; a condition characterized by a chronic exposition to calorie surplus. Our report extends the available information by showing that BMI, fasting plasma glucose, uric acid, and physical activity are all independently associated with serum FGF21 levels. Increased free fatty acid concentration is also a feature of obesity (29). This abnormality may be the mechanism explaining the observed association between BMI and FGF21 levels. In the metabolic syndrome, the excess lipids enter alternative nonoxidative pathways resulting in the production of toxic reactive lipid species. Therefore, FGF21 by inhibiting lipogenesis and increasing fatty acid utilization may play a compensatory role against the metabolic defects associated with obesity. Some of the FGF21 actions that participate in the adaptation to fasting may limit the ectopic deposition of lipids in obese individuals. However, to confirm this theory, more research is needed. The association between glycemia and FGF21 
Table 4 Serum fibroblast growth factor 21 (FGF21) levels according to joint categories of glucose, uric acid, and body mass index with physical activity level.

\begin{tabular}{|c|c|c|c|c|c|}
\hline \multirow[b]{2}{*}{ Condition } & \multirow[b]{2}{*}{$\boldsymbol{n}(\%)$} & \multicolumn{2}{|c|}{ Physical activity (kcal/day) } & \multicolumn{2}{|c|}{ Statistics } \\
\hline & & Tertile 2 & Tertile 3 & $t$ & $P$ \\
\hline Physical activity ${ }^{a}$ & $167(100)$ & 61.3 & 132.7 & 3.9 & $<0.001$ \\
\hline Glucose $\geq 100 \mathrm{mg} / \mathrm{dl}^{\mathrm{a}}$ & $16(9.6)$ & 63.2 & 113.3 & 3.8 & $<0.001$ \\
\hline Glucose $<100 \mathrm{mg} / \mathrm{dl}^{\mathrm{a}}$ & $151(90.4)$ & 19.4 & 31.2 & 2.3 & 0.02 \\
\hline $\mathrm{BMI} \geq 25 \mathrm{~kg} / \mathrm{m}^{2 \mathrm{~b}}$ & $116(69.5)$ & 92.3 & 109.3 & 3.4 & 0.001 \\
\hline $\mathrm{BMI}<25 \mathrm{~kg} / \mathrm{m}^{2 \mathrm{~b}}$ & $51(30.5)$ & 15.0 & 31.2 & 2.2 & 0.04 \\
\hline Uric acid $\geq 5.5 \mathrm{mg} / \mathrm{dl}^{\mathrm{a}}$ & $82(49.1)$ & 29.1 & 118.7 & 3.1 & $<0.001$ \\
\hline Uric acid $<5.5 \mathrm{mg} / \mathrm{dl}^{\mathrm{a}}$ & $85(50.9)$ & 12.5 & 21.8 & 2.8 & 0.021 \\
\hline
\end{tabular}

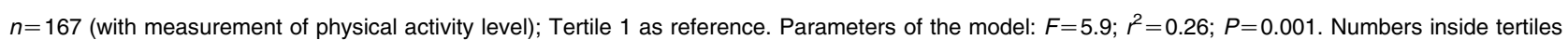
columns represent change in serum FGF21 (ng/l) when condition is present.

aSerum FGF21 levels adjusted for age and BMI.

${ }^{\mathrm{b}}$ Serum FGF21 levels adjusted for age.

levels is in line with this interpretation. The FGF21 overproduction may counterbalance the deleterious effects of free fatty acids on insulin action and glucose disposal. An alternative explanation may be that obesity and hyperglycemia cause an impaired tissue response to FGF21 leading to increased concentrations of this hormone. This alternative explanation implies that FGF21 has a regulatory axis, in which its own plasma level may be a determinant. Hence, we propose that FGF21 may form part of a defense response against the damaging effects of a chronic exposition to increased plasma fatty acid concentrations. Clearly, additional studies in humans and in animal models are required to describe FGF21 physiology.

Our data also show that daily physical activity has a positive association with serum FGF21 levels. Physical activity stimulates lipolysis $(30,31)$, increases serum free fatty acids, and activates PPAR- $\alpha$-regulated pathways such as that of FGF21 secretion. This could explain the direct association identified between physical activity and FGF21.

Additionally, we report a novel association between uric acid and FGF21. Studies in healthy volunteers have shown that PPAR- $\alpha$ activation increases urinary uric acid excretion (32). In accordance, fenofibrate (a PPAR- $\alpha$ activator) lowers serum uric acid levels (33). However, it is not clear how uric acid plasma levels may increase FGF21 secretion. Hyperuricemia is frequently associated with the metabolic syndrome (34). This abnormality has been linked to endothelial dysfunction, decreased nitric oxide synthesis, and arterial hypertension (35). Additional studies are needed to confirm the participation of uric acid in FGF21 physiology.

In our study, BMI, physical activity, and plasma levels of glucose and uric acid explained only $20 \%$ of the variation in FGF21 concentrations. Other factors must be involved in the regulation of FGF21. For example, we found a negative association between FGF21 and RBP4, total, and HMW adiponectin. However, these associations lost their statistical significance in multivariate analysis. Adiponectin has been associated with insulin-sensitizing actions (36). Patients with insulin resistance and the metabolic syndrome have lower HMW and total adiponectin levels compared with their control peers (15). Based on this, the negative association between total and HMW adiponectin and FGF21 is predictable. Additional studies are required to confirm the potential interrelationships existing between these two hormones. Finally, RBP4 is another adipokine that may be associated with FGF21 physiology; a negative association between RBP4 and FGF21 was found in women. This relationship could be gender specific but needs confirmation. However, an alternative explanation is a sample size effect. The number of women included in our study sample was double that of the number of men.

Some limitations of this study must be recognized. Indirect estimates of insulin sensitivity (instead of the euglycemic clamp technique) were used in our report. This may limit our ability to identify associations between insulin sensitivity and FGF21. In addition, we did not measure circulating FFA levels, or the urinary excretion of uric acid. The prevalence of the metabolic syndrome in our cohort was relatively high, and the results of this study are applicable only to similar populations.

\section{Supplementary data}

This is linked to the online version of the paper at http://dx.doi.org/ 10.1530/EJE-10-0454.

\section{Declaration of interest}

The authors declare that there is no conflict of interest that could be perceived as prejudicing the impartiality of the research reported.

\section{Funding}

This research did not receive any specific grant from any funding agency in the public, commercial, or not-for-profit sector. 


\section{Acknowledgements}

We express our depth gratitude to Luz Elizabeth Guillén-Pineda and the laboratory personnel of the Department of Endocrinology and Metabolism for their technical support.

\section{References}

1 Kharitonenkov A, Shiyanova TL, Koester A, Ford AM, Micanovic R, Galbreath EJ, Sandusky GE, Hammond LJ, Moyers JS, Owens RA, Gromada J, Brozinick JT, Hawkins ED, Wroblewski VJ, Li DS, Mehrbod F, Jaskunas SR \& Shanafelt AB. FGF-21 as a novel metabolic regulator. Journal of Clinical Investigation 2005115 1627-1635.

2 Nishimura T, Nakatake Y, Konishi M \& Itoh N. Identification of a novel FGF, FGF-21, preferentially expressed in the liver. Biochimica et Biophysica Acta 20001492 203-206.

3 Inagaki T, Dutchak P, Zhao G, Ding X, Gautron L, Parameswara V, Li Y, Goetz R, Mohammadi M, Esser V, Elmquist JK, Gerard RD, Burgess SX, Hammer RE, Mangelsdorf DJ \& Kliewer SA. Endocrine regulation of the fasting response by PPAR-alfa-mediated induction of FGF21. Cell Metabolism 20075 415-425.

4 Badman MK, Pissios P, Kennedy AR, Koukos G, Flier JS \& MaratosFlier E. Hepatic fibroblast growth factor 21 is regulated by PPARalfa and is a key mediator of hepatic lipid metabolism in ketotic states. Cell Metabolism 20075 426-437.

5 Arner P, Pettersson A, Mitchell PJ, Dunbar JD, Kharitonenkov A \& Rydén M. FGF21 attenuates lipolysis in human adipocytes - a possible link to improved insulin sensitivity. FEBS Letters 2008 $\mathbf{5 8 2} 1725-1730$

6 Kharitonenkov A, Wroblewski WJ, Koester A, Chen YF, Clutinger CK, Tango XT, Hansen BC, Shanafelt AB \& Etgen GJ. The metabolic state of diabetic monkeys is regulated by FGF21. Endocrinology 2007148 774-781.

7 Mai K, Andres J, Biedasek K, Weicht J, Bobbert T, Sabath M, Meinus S, Reinecke F, Möhlig M, Weickert MO, Clemenz M, Pfeiffer A, Kintscher U, Spuler S \& Spranger J. Free fatty acids link metabolism and regulation of the insulin-sensitizing fibroblast growth factor-21. Diabetes $2009 \mathbf{5 8} 1532-1538$.

8 Chavez AO, Molina-Carrion M, Abdul-Ghani MA, Folli F, DeFronzo RA \& Tripathy D. Circulating fibroblast growth factor21 (FGF-21) is elevated in impaired glucose tolerance and type 2 diabetes and correlates with muscle and hepatic insulin resistance. Diabetes Care 200932 1542-1546.

9 Zhang X, Yeung DC, Karpisek M, Stejskal D, Zhou ZG, Liu F, Wong RL, Chow WS, Tso AW, Lam KS \& Xu A. Serum FGF21 levels are increased in obesity and are independently associated with the metabolic syndrome in humans. Diabetes $2008 \mathbf{5 7}$ 1246-1253.

10 Huating Li, Yuqian Bao, Aimin Xu, Xiaoping Pan, Junxi Lu, Haiya Wu, Huijuan Lu, Kunsan Xiang \& Weiping Jia. Serum fibroblast growth factor 21 is associated with adverse lipids profiles and $\gamma$-glutamyltransferase but not insulin sensitivity in chinese subjects. Journal of Clinical Endocrinology and Metabolism 200994 2151-2156.

11 Chen WW, Li L, Yang GY, Li K, Oi XY, Zhu W, Tang Y, Liu H \& Boden G. Circulating FGF21 levels in normal subjects and in newly diagnose patients with type 2 diabetes mellitus. Experimental and Clinical Endocrinology \& Diabetes 2007116 65-68.

12 Yang Q, Graham TE, Mody N, Preitner F, Peroni OD, Zabolotny JM, Kotani K, Quadro L \& Kahn BB. Serum retinol binding protein 4 contributes to insulin resistance in obesity and type 2 diabetes. Nature 2005436 356-362.

13 Janke J, Engeli S, Boschmann M, Adams F, Böhnke J, Luft FC, Sharma AM \& Jordan J. Retinol-binding protein 4 in human obesity. Diabetes 200655 2805-2810.

14 Diez JJ \& Iglesias P. The role of the novel adipocyte-derived hormone adiponectin in human disease. European Journal of Endocrinology 2003148 293-300.
15 Hara K, Horikoshi M, Yamauchi T, Yago H, Miyazaki O, Ebinuma H, Imai Y, Nagai R \& Kadowaki T. Measurement of the high-molecular weight form adiponectin in plasma is useful for the prediction of insulin resistance and metabolic syndrome. Diabetes Care 200629 1357-1362.

16 Xu A, Chan KW, Hoo RL, Wang Y, Tan KC, Zhang J, Chen B, Lam MC, Tse C, Cooper GJ \& Lam KS. Testosterone selectively reduces the high molecular weight form of adiponectin by inhibiting its secretion from adipocytes. Journal of Biological Chemistry $200528018073-18080$.

17 Expert Panel on Detection, Evaluation, and Treatment of High Blood Cholesterol in Adults. Executive Summary of The Third Report of The National Cholesterol Education Program (NCEP) Expert Panel on Detection, Evaluation, and Treatment of High Blood Cholesterol in Adults (Adult Treatment Panel III). Journal of the American Medical Association 2001285 2486-2497.

18 Grundy SM, Cleeman JI, Daniels SR, Donato KA, Eckel RH, Franklin BA, Gordon DJ, Krauss RM, Savage PJ, Smith SC Jr, Spertus JA \& Costa F. Diagnosis and management of the metabolic syndrome: and American Heart Association/National Heart, Lung and Blood Institute Scientific Statement. Circulation 2005112 $2735-2752$

19 Matthews DR, Hosker JO, Rudenski AS, Naylor BA, Treacher DF \& Turner RC. Homeostasis model assessment: insulin resistance and beta-cell function from fasting plasma glucose and insulin concentration in man. Diabetologia 198528 412-419.

20 López-Alvarenga JC, Reyes-Díaz S, Castillo-Martínez L, DávalosIbáñez A \& González-Barranco J. Reproducibility and sensitivity of a questionnaire on physical activity in a Mexican population. Salud Pública de México 200143 306-312.

21 Baecke JA, Burema J, Frijters JE, Hautvast JG \& Van der WielWetzels WA. Obesity in young Dutch adults: II, Daily life style and body mass index. International Journal of Obesity 19837 13-24.

22 Paffenbarger RS, Wing AL \& Hyde RT. Physical activity as an index of heart attack risk in college alumni. American Journal of Epidemiology 1978108 161-175.

23 Lundasen T, Hunt MC, Nilsson LM, Sanyal S, Angelin B, Alexson SHE \& Rudling M. PPAR-alfa is a key regulator of hepatic FGF21. Biochemical and Biophysical Research Communications 2007 $360437-440$

24 Potthoff MJ, Inagaki T, Satapati S, Ding X, He T, Goetz R, Mohammadi M, Finck BN, Mangelsdorf DJ, Kliewer SA \& Burgess SC. FGF21 induces PGC-1alfa and regulates carbohydrate and fatty acid metabolism during the adaptive starvation response. PNAS 2009106 10853-10858.

25 Coskun T, Bina HA, Schneider MA, Dunbar JD, Hu CC, Chen Y, Moller DE \& Kharitonenkov A. Fibroblast growth factor 21 corrects obesity in mice. Endocrinology $20081496018-6027$.

26 Kliewer SA \& Mangelsdorf DJ. Fibroblast growth factor 21: from pharmacology to physiology. American Journal of Clinical Nutrition $201091254 \mathrm{~S}-257 \mathrm{~S}$

27 Hojman P, Pedersen M, Nielsen RA, Krogh-Madsen R, Yfanti Ch, Akerstrom Th, Nielsen S \& Pedersen BK. Fibroblast growth factor21 is induced in human skeletal muscles by hyperinsulinemia. Diabetes 200958 2797-2801.

28 Gälman C, Lundasen T, Kharinonekov A, Eriksson M, Haström I, Dahlin M, Amark P, Angelin B \& Rudling M. The circulating metabolic regulator FGF21 is induced by prolonged fasting and PPAR- $\alpha$ activation in man. Cell Metabolism 20088 169-174.

29 Boden G. Obesity and free fatty acids. Endocrinology and Metabolism Clinics of North America 200837 635-646.

30 Chatzinikolaou A, Fatouros I, Petridou A, Jamurtas A, Avloniti A, Douroudos I, Mastorakos G, Lazaropoulou Ch, Papassotiriou I, Tournis S, Mitrakou A \& Mougios V. Adipose tissue lipolysis is upregulated in lean and obese men during acute resistance exercise. Diabetes Care 200831 1397-1399.

31 Alsted TJ, Nybo L, Schwelger M, Fledelius C, Jacobsen P, Zimmermann R, Zechner R \& Kiens B. Adipose triglyceride lipase in human skeletal muscle is upregulated by exercise training. American Journal of Physiology. Endocrinology and Metabolism 2009 296 E244-E253. 
32 Patterson AD, Slanar O, Krausz KW, Höfer CC, Perlík F, Gonzalez FJ \& Idle JR. Human urinary metabolomic profile of PPAR-alfa induced fatty acid beta-oxidation. Journal of Proteome Research 20098 4293-4300.

33 Kiortsis DN \& Elisaf MS. Serum uric acid levels: a useful but not absolute marker of compliance with fenofibrate treatment. Fundamental \& Clinical Pharmacology 200115 401-403.

34 Suzuki I, Yamauchi T, Onuma M \& Nozaki S. Allopurinol, an inhibitor of uric acid synthesis; can it be used for the treatment of metabolic syndrome and related disorders? Drugs of Today 2009 45 363-378.
35 Johnson RJ, Kang DH, Feig D, Kivlighn S, Kanellis J, Watanabe S, Tuttle KR, Rodriguez-Iturbe B, Herrera-Acosta J \& Mazzali M. Is there a pathogenic role for uric acid in hypertension and cardiovascular and renal disease? Hypertension 200341 1183-1190.

36 Kadowaki $\mathrm{T} \&$ Yamauchi T. Adiponectin and adiponectin receptors. Endocrine Reviews 200526 439-451.

Received 2 June 2010

Accepted 21 June 2010 